\title{
Supplemented Creatine Induces Changes in Human Metabolism of Thiocompounds and One- and Two-Carbon Units
}

\author{
T. NAVRÁTIL ${ }^{1}$, E. KOHLÍKOVÁ ${ }^{2}$, M. PETR ${ }^{2}$, D. PELCLOVÁ ${ }^{3}$, M. HEYROVSKÝ ${ }^{1}$, \\ K. PřISTOUPILOVÁ ${ }^{4}$
}

${ }^{1}$ J. Heyrovský Institute of Physical Chemistry, Academy of Sciences of the Czech Republic, Prague, ${ }^{2}$ Charles University in Prague, Faculty of Physical Education and Sport, Department of Physiology and Biochemistry, Prague, ${ }^{3}$ Charles University in Prague, First Faculty of Medicine, Department of Occupational Medicine, Prague, ${ }^{4} \mathrm{Na}$ Hřebenkách 19, Prague, Czech Republic

Received April 26, 2008

Accepted December 15, 2008

On-line February 27, 2009

\section{Summary}

The administration of creatine ( $5 \mathrm{~g} /$ day for one month) to 11 young active sportsmen affected their urinary excretion of creatine, creatinine, and thiodiglycolic acid (TDGA) as well as blood levels of homocysteine, vitamin $B_{12}$ and folates. The probands were divided into four groups, according to the amount of creatine found in urine, and of folates and vitamin $B_{12}$ determined in blood. The changes of folates and vitamin $B_{12}$ were mutually reciprocal. Each group utilized $\mathrm{CR}$ as donor of one- and two-carbon (1C and $2 \mathrm{C}$ ) units by means of homocysteine (HoCySH), folates, and vitamin $B_{12}$, in different metabolic pathways. In 10 men the creatine administration was accompanied by an increase of HoCySH level in blood, while in the last man, with accidentally discovered hyperhomocysteinemia, the HoCySH level dropped by $50 \%$. Differences between initial and terminal TDGA levels indicate that creatine affects equilibria of redox processes. Creatinine excretion into urine changed in the dependence on the extent of metabolic disturbances.

\section{Key words}

Creatine - Creatinine - Folates - Homocysteine - Vitamin $\mathrm{B}_{12} \bullet$ Thiodiglycolic acid (TDGA) • Voltammetry • Urine • Blood

\section{Corresponding author}

Tomáš Navrátil, J. Heyrovský Institute of Physical Chemistry of AS CR, v.v.i., Dolejškova 3, 18223 Prague 8, Czech Republic. E-mail: navratil@jh-inst.cas.cz

\section{Introduction}

Creatine (CR) is an amino acid (methyl guanidine acetic acid), which represents one of the most important nitrogen containing compounds playing a role in energetic metabolism. A certain part of exogenously applied CR is retained in human body (Webber 2006).

$\mathrm{CR}$ is not an essential component of food, because it is formed naturally in human body. It represents about $0.17 \%$ of body mass, of which $95 \%$ is in skeletal muscles and $5 \%$ in brain, kidneys, liver and testicles (Persky and Brazeau 2001), and a small part in blood plasma (Webber 2006). Two thirds of CR are present in the human body as creatine phosphate (CR phosphate), the rest as free CR (Webber 2006). In normal healthy men the turnover of $\mathrm{CR}$ is about $1-2 \mathrm{~g}$ daily, which is covered by its endogenous synthesis from amino acids (arginine, glycine, methionine) in liver and kidneys (Murray et al. 2003), and by food intake (from animal sources as meat). Under these conditions the same amount (about $2 \mathrm{~g}$ daily) of CR is degraded by nonenzymatic dehydration to creatinine and excreted into urine (Murray et al. 2003).

It is recommended to apply $\mathrm{CR}$ as food supplement in amounts corresponding to its natural level in meaty food. It is supposed that the human organism uses it for the formation of CR phosphate, which is necessary as energetic source for muscular work.

Exogenously applied CR is used in treatment of neurodegenerative diseases - dystrophy, myalgia, 
rheumatoid arthritis, etc. (Felber et al. 2000, Petr 2007, Tarnopolsky and Martin 1999). More than 5 million $\mathrm{kg}$ of CR is sold yearly through the world (Hespel et al. 2001), mostly for purposes of food supplement for sportsmen.

$\mathrm{CR}$ has been used for more than 15 years intensively as food supplement as well as remedy; however, up to now the question concerning the safety of its application has not been answered. Each of the previously published studies concentrates on a certain specific problem of its application. Their results and conclusions are influenced by the extent and arrangement of experiments. On the basis of published results it is possible to unambiguously conclude that $\mathrm{CR}$ application increases the muscle mass and volume of body fluid, formation of ATP and body performance connected with short-time load (Petr 2007). With its increasing application many metabolic questions have to be answered to explain the risks and consequences of $\mathrm{CR}$ supplementation.

We have proved in other experiments (Navratil et al. 2009) that within 4 to 6 hours after CR supplementation the level of thiodiglycolic acid (TDGA) in urine rapidly increases and then decreases again to its original level. At the same time urinary $\mathrm{pH}$ values increase by 1.5 units (Navratil et al. 2009). The changes in TDGA excretion indicated that exogenous application of $\mathrm{CR}$ affects metabolic pathways of thiocompounds and of two-carbon (2C) units. The effect of CR on TDGA excretion differs from those recorded after vitamin $B_{12}$, and betaine applications (Navratil et al. 2007).

At present, the voltammetric determination of TDGA in urine (Chylkova and Fadrna 2004, Samcova et al. 1999) is being used in toxicology (Dlaskova et al. 2003). It helps to monitor the exposure of workers in chemical plants to certain carcinogenic compounds, e.g. to vinylchloride monomer (VCM) or ethylene dichloride (EDC) in factories producing polyvinyl chloride (Dlaskova et al. 2003, Senholdova-Dlaskova 2002). Similarly as in the case of VCM exposure, the TDGA level in urine increases after the intake of some remedies (Navratil et al. 2004), victuals (Navratil et al. 2004), compounds with organically bound sulfur (Steventon 1999) or compounds, which affect oxidative metabolic pathways accompanied by release of $2 \mathrm{C}$ units, e.g. ethanol, VCM (Navratil et al. 2004) or mustard gas (Ermakova et al. 2002, Lee et al. 2000). In intoxicated humans, these $2 \mathrm{C}$ units, which take part in the formation of TDGA, originate from xenobiotics. The oxidative degradation of xenobiotics via TDGA formation decreases the cell pool of glutathione (GSH). In some critical cases all disposable GSH can be exhausted (Murray et al. 2003). This endangers all metabolic pathways dependent on the presence of GSH.

The TDGA concentrations determined in samples of urine in healthy individuals (Dlaskova et al. 2003) do not exceed $20 \mathrm{mg} \cdot \mathrm{l}^{-1}$. We suppose that in healthy humans the source of $2 \mathrm{C}$ units is serine or glycine. The thiolic part of the TDGA molecule comes from cysteine. The urinary level of TDGA increases only by imbalance between oxidative release of $2 \mathrm{C}$-units and supply of thiocompounds and oxygen (Ermakova et al. 2002). TDGA is merely one of the intermediates in this oxidative pathway of $2 \mathrm{C}$ unit bound to cysteine. TDGA is excreted into urine, due to imbalance in its formation and further degradation. One of the final oxidative products of TDGA is sulfate, which might be later used (after reaction with ATP) as active sulfate (PAPS), e.g. for the synthesis of collagen.

The present study is aimed to shed more light on some of the above mentioned questions, to search for relationship among levels of various compounds in blood or urine, and body parameters connected with $\mathrm{CR}$ metabolism. In our study we wanted to show how CR, given as food supplement, affects its related metabolic pathways and the TDGA excretion into urine. From the analytical point of view, this illustrates the necessity to use wide range of analytical techniques (electrochemistry, chromatography, spectrophotometry, etc.) in order to gain complete, reasonable and reliable results.

\section{Methods} Proband group characterization, sampling and $C R$
supplementation

Group of volunteers consisted of 11 young men, students of Faculty of Physical Education and Sport, aged 21-28 years (on average 24.6 year). Women were not subjected to the present study due to complicated hormonal changes during month, which affect cell water content substantially. All probands were young, healthy, physically active persons, dealing with sportive activities (ice hockey, football, horsemanship, and athletics) on professional level. The sportive activities were very carefully observed, however, they were not consistent. All probands signed the informed consent. None of the volunteers was taking any other food supplement, stimulant, drugs or vitamin preparation during this study.

Because all the sportsmen, who were subjects of 
the reported study, took part in some similar (short time) experiments (results of which were reported in earlier published studies (Navratil et al. 2009)), we could evaluate the changes in their body weights in course of a few last months. We can therefore conclude that regardless of sport activities, the body weight of the sportsmen was practically constant before the start of the testing.

During the time of CR supplementation and one day before, none of the volunteers consumed victuals containing onion or garlic, alcohol (Dlaskova et al. 2003, Chylkova and Fadrna 2004, Navratil et al. 2004), remedies containing carboxymethyl cysteine (ACC 100 etc.) or higher content of organically bound sulfur, and $\mathrm{B}_{12}$ vitamin, folic acid (Navratil et al. 2007, Pristoupilova et al. 2005). They drank about 2 liters of fluids per day. We can characterize their nutrition as almost standardized.

"CR-monohydrate - a special nutritional supplement for athletes" (Plutino, Czech Republic) was administered per os (p. o.) in $5 \mathrm{~g}$ doses, diluted in tepid water. These doses were administered every morning (at about 8 a.m.) for 30 days.

Blood and urine of each proband were sampled, and body impedance was measured on the first day (before the first CR application) and on the last day (after the last CR dose application). The samples were taken in the morning at fasted state. All collected urine samples, which were not analyzed on the day when they were taken, were immediately frozen to $-18{ }^{\circ} \mathrm{C}$ and were then defrozen just before the analysis (Navratil et al. 2004, Senholdova-Dlaskova 2002). $\Delta$-value, used for individual characterization of probands, was calculated for each parameter as difference between the values determined in the samples of urine and blood on the last and on the first day.

There were evaluated 35 parameters in each person (Petr 2007).

\section{Creatinine and $C R$ determination}

Determination of creatinine was based on Jaffe reaction realized in alkaline solution, i.e. on its nucleophilic addition, on benzene ring of picric acid under formation of red colored creatine picrate, the concentration of which can be determined using a spectrophotometer at $530 \mathrm{~nm}$ (Bardodej et al. 1989). CR in the sample must be completely transformed to creatinine and after that analyzed as part of total creatinine. The difference between the results recorded in the second and in the first analysis corresponds to the amount of CR in the sample. $0.1 \mathrm{ml}$ of analyzed urine is to be mixed with $1 \mathrm{ml}$ of $0.1 \mathrm{M} \mathrm{NaOH}$ and $5 \mathrm{ml}$ of saturated solution of picric acid and the solution is to be stirred. After $10 \mathrm{~min}$ the mixture is to be filled up to $25 \mathrm{ml}$ with distilled water and the formed complex is to be analyzed spectrophotometrically at $530 \mathrm{~nm}$ in glass cuvettes. Afterwards the CR present in the sample is to be transformed to creatinine by acidification and boiling ( 2 hours) in a water bath. The evaporated volume of water must be added to the sample after cooling to laboratory temperature. The total amount of creatinine is determined spectrophotometrically at $530 \mathrm{~nm}$, too (Bardodej et al. 1989).

All parameters in blood were determined in a commercial laboratory Klinlab, Prague, Czech Republic (KlinLab 2010a), using commonly applied methods (KlinLab 2010b). The blood was analyzed till $30 \mathrm{~min}$ after sampling.

\section{Determination of vitamin $B_{12}$}

Vitamin $\mathrm{B}_{12}$ was determined using the competitive binding immunochemiluminescence “Access ${ }^{\circledR}$ vitamin $B_{12}$ set”, supplied by the company Beckman Coulter, Inc. (Beckman_Coulter 2008). The blood sample is mixed with solution of $\mathrm{NaOH}, \mathrm{KCN}$ and dithiothreitol (DTT) and incubated at $36.5^{\circ} \mathrm{C}$ for $5 \mathrm{~min}$. All forms of vitamin $B_{12}$ are transformed into cyanocobalamine and the binding proteins are denatured. The paramagnetic particles are impregnated by goat binding antibody against mice immunoglobulins with mice monoclonal antibody against intrinsic factor. Porcine intrinsic factor alkaline phosphatase conjugate is added and the sample is incubated at $36.5^{\circ} \mathrm{C}$ for $20 \mathrm{~min}$ to realize the competitive binding. Vitamin $B_{12}$ conjugates with intrinsic factor and competes in binding on the solid phase (Beckman_Coulter 2008). The particles are separated in magnetic field and the unbound compounds are washed out. The chemiluminescence substrate Lumi-Phos 530 is added and the eradiated red light is measured using a luminometer (after addition of dioxyetane-P). The number of produced photons is indirectly proportional to the vitamin $\mathrm{B}_{12}$ concentration in the sample. Detailed instructions are available on request by Beckman Coulter Inc. (Beckman_Coulter 2004).

The applied procedure cannot distinguish among different forms of vitamin $\mathrm{B}_{12}$ (total, bound on the binding proteins (transcobalamin and haptocorrin) (Wickramasinghe and Fida 1993), because all binding 
proteins are denatured before start of the determination. Hence, the estimation of "active Vitamin B-12"Holotranscobalamin has not been used.

\section{Determination of folates}

Folates were determined using similar principle the competitive binding immunochemiluminescence “Access ${ }^{\circledR}$ Folate set" supplied by the company Beckman Coulter, Inc. (Beckman_Coulter 2004). The determination of folates in plasma or serum does not require any sample pretreatment. In case of analysis in erythrocytes ascorbic acid or serum albumin without folates must be added to the blood sample. This way prepared sample is called hemolysate. The folates must be released from endogenous binding proteins. After neutralization, binding proteins of folates - mice immunoglobulins on magnetic particles are added. Folates from the sample after reaction with alkaline phosphatase compete with mice immunoglobulins for binding sites on goat binding protein for folates. (Beckman_Coulter 2004). The particles are separated in magnetic field and the unbound compounds are washed out. The chemiluminescence substrate Lumi-Phos 530 is added and the eradiated red light is measured using a luminometer. The number of produced photons is indirectly proportional to the folate concentration in the sample. Detailed instructions are available on request by Beckman Coulter Inc. (Beckman_Coulter 2004).

\section{Determination of homocysteine}

Homocysteine (HoCySH) was determined according to the "Diazyme" method described in (Dou et al. 2005). This method is based on co-substrate conversion of the determined substance in a circle. Oxidized HoCySH is transformed to the free one, which reacts first with co-substrate $S$-adenosylmethionine (S-AM) using enzyme homocysteine-S-methyltransferase to methionine and S-adenosylhomocysteine (S-AH). $\mathrm{S}-\mathrm{AH}$ is hydrolyzed to adenosine and homocysteine using S-AH hydrolase. The newly formed homocysteine from co-substrate S-AM represents a part of cyclic enzymatic system. Adenosine is decomposed to inosine and ammonia, which further reacts with glutamate dehydrogenase under simultaneous transformation of $\mathrm{NADH}$ to $\mathrm{NAD}^{+}$. HoCySH concentration in the sample is proportional to the amount of NADH converted to NAD ${ }^{+}$. The detailed instructions are available on request by Beckman Coulter Inc. (Beckman_Coulter 2004).
Chemicals used were of analytical reagent purity grade. Double distilled water was applied throughout the work (conductivity $<1 \mu \mathrm{S} . \mathrm{cm}^{-1}$ ). All measurements were carried out at room temperature.

\section{Determination of TDGA}

Special attention was paid to voltammetric determinations of TDGA, which are not common in medical laboratories. Urine samples were analyzed by the voltammetric technique described in our previous paper (Dlaskova et al. 2003). The preparation of the sample was made in a column of powdered PVC, the urine sample was transferred to the top of the column and eluted by $0.2 \mathrm{M}$ perchloric acid. The resulting eluate was introduced into the electrolytic cell, deaerated by a stream of nitrogen (purity $99.999 \%$ ), and then subjected to direct current (D.C.) voltammetric analysis. The measurement was started by accumulation for $10 \mathrm{~s}$ under stirring at the initial potential of $-800 \mathrm{mV}$ vs. $\mathrm{Ag} / \mathrm{AgCl} / 1 \mathrm{~mol}^{-1} \mathrm{KCl}$, followed by rest period of $15 \mathrm{~s}$, and then by potential scan at the rate of $-10 \mathrm{mV} \cdot \mathrm{s}^{-1}$ to the final potential of $-1200 \mathrm{mV}$. The values of potentials given in this paper are referred to that of $\mathrm{Ag} / \mathrm{AgCl}$ reference electrode, which is at $25^{\circ} \mathrm{C}$ by $9 \mathrm{mV}$ more negative than the SCE. All experiments were carried out at room temperature $\left(25 \pm 2{ }^{\circ} \mathrm{C}\right)$. For quantitative evaluation the method of double standard addition was used.

\section{Urinary data expression}

TDGA, CR and creatinine were corrected for specific gravity of urine, whereas TDGA and CR were corrected for urinary creatinine. The corrections for specific gravity were calculated by means of Eq. (1) (Bardodej et al. 1989, Pristoupilova et al. 2005). In calculations it is assumed that the mean reference value of the specific gravity of human urine is $1.020 \mathrm{~g} \cdot \mathrm{ml}^{-1}$.

$$
X_{\text {cor }}=X \frac{0.020}{s \cdot g \cdot-1}
$$

where $X_{\text {cor }}$ denotes the corrected value (TDGA/s.g. $\left[\mathrm{mg} . \mathrm{l}^{-1}\right], \mathrm{CR} / \mathrm{s} . \mathrm{g}$. [g. $\left.\mathrm{l}^{-1}\right]$, etc. respectively), $X$ denotes the value without corrections (TDGA $\left[\mathrm{mg} . \mathrm{l}^{-1}\right], \mathrm{CR}\left[\mathrm{g} \cdot \mathrm{l}^{-1}\right]$, creatinine $\left[\mathrm{g} . \mathrm{l}^{-1}\right]$ respectively), s.g. denotes the urine specific gravity $\left[\mathrm{g} \cdot \mathrm{ml}^{-1}\right]$. If not otherwise specified, the values of TDGA, creatinine and CR in the whole text are given after corrections per specific gravity. 
Table 1. Changes in blood levels of vitamin $B_{12}$, folates in blood and urinary creatine after 30 days of creatine application.

\begin{tabular}{llccc}
\hline Group & Proband No. & Vitamin $\mathbf{B}_{\mathbf{1 2}}$ & $\begin{array}{c}\text { Changes in levels of } \\
\text { Folates }\end{array}$ & Creatine \\
\hline$A$ & $1,2,3$ & - & + & + \\
$B$ & 4 & + & + & + \\
$C$ & $5,6,7$ & + & - & + \\
$D$ & $8,9,10,11$ & + & - & - \\
\hline
\end{tabular}

\section{Apparatus}

The analysis of TDGA was carried out by the computer-controlled Eco-Tribo Polarograph using the software "Polar 5.1" version for Windows (PolaroSensors, s.r.o., Czech Republic), on pen-type hanging mercury drop electrode (HMDE) (Polaro-Sensors, s.r.o., Czech Republic), on mercury meniscus modified silver solid amalgam electrode (Barek et al. 2003, Barek et al. 2006, Yosypchuk and Novotny 2002a, Yosypchuk and Novotny 2002b), or on solid composite electrode (Barek et al. 2007, Navratil and Kopanica 2002a, Navratil and Kopanica 2002b, Navratil et al. 2003, Sebkova et al. 2004, Sebkova et al. 2005, Yosypchuk et al. 2007). The results, achieved using all three above mentioned working electrodes, were equivalent. More precisely, the calculated confidence intervals of results overlapped with probability higher than $95 \%$. The shapes of recorded curves with all three tested electrodes were similar; the peak positions and peak shapes were similar as well. Nevertheless, the determinations realized with electrode containing liquid mercury, i.e. HMDE, exhibited the highest sensitivity and the lowest background. HMDE was the most "user friendly", its surface was the easiest and the fastest renewable, the repeatability of results achieved by it was the best. Smaller amount of mercury on the electrode surface (mercury meniscus, mercury film, polished amalgam surface or amalgam composite surface) causes smaller sensitivity to TDGA concentration. Responses of such electrodes are lower and worse reproducible. The highest background and the lowest sensitivity were recorded with composite electrodes. Therefore, in most experiments presented in this manuscript, the HMDE was used (Navratil et al. 2009).

$\mathrm{CR}$ and creatinine were determined using Specord 200. pH was measured by digital laboratory pH-meter Inolab (Benella CZ, Praha). The specific gravities of urine samples were determined using laboratory glass densitometer for liquids in the range from 1000-1050 kg.m ${ }^{-3}$ (Exatherm, Jablonec n. N., Czech Republic). The levels of folates, vitamin $\mathrm{B}_{12}$ and homocysteine (HoCySH) in blood were determined in a commercial laboratory (Klinlab, s.r.o., Prague, Czech Republic) (KlinLab 2010a) by standard methods, described above. The levels of the other evaluated parameters (TDGA, CR, creatinine in urine, its $\mathrm{pH}$ and specific gravity) were determined in authors' laboratory.

\section{Statistics}

For evaluation of the results several statistical tests were used. The outlying points (diagnosed by DeanDixon and Grubbs tests) could not be eliminated, because each result has its importance and must be taken into account. The calculations were realized using MS Excel 2003 (Microsoft Corporation, USA), software Adstat 2.0 and QC Expert (both TriloByte, Czech Republic), Statistica (StatSoft CR, s.r.o., Czech Republic).

\section{Results}

After a month of CR application it was possible to divide eleven volunteers into four groups - A, B, C, $\mathrm{D}$, according to changes in the levels of vitamin $\mathrm{B}_{12}$ and folates in blood, and of CR in urine, irrespective of the absolute values (Table 1). These men were numbered from 1 to 11 . The content of unused $\mathrm{CR}$ in urine increased in the group A (probands No. 1, 2, and 3), in the group B (proband No. 4) and in the group C (probands No. 5, 6, and 7). On the contrary, in the group D (probands No. 8, 9, 10 and 11) urinary CR was decreased or even disappeared. In blood of the group A the level of folates increased, while the level of vitamin $\mathrm{B}_{12}$ decreased, in contrast to groups $\mathrm{B}, \mathrm{C}$ and $\mathrm{D}$, where the levels changed in the opposite direction. 


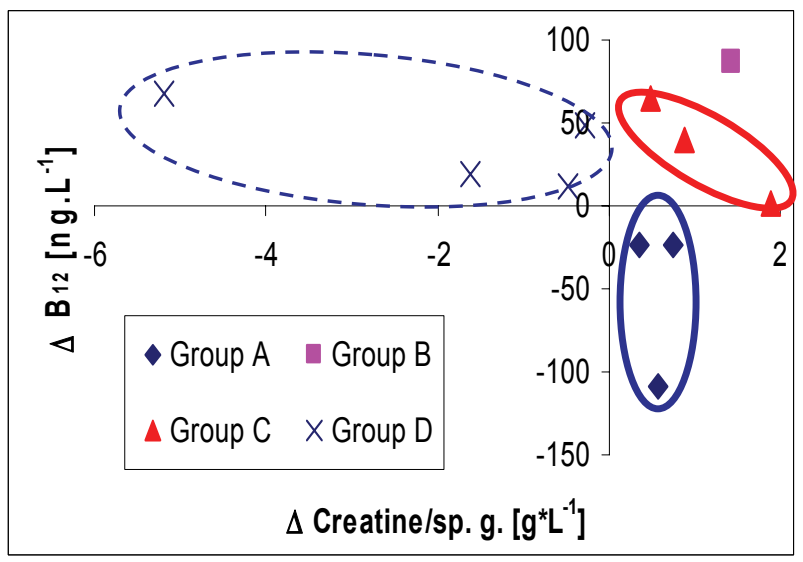

Fig 1. The changes of vitamin $B_{12}$ in the blood $\left(\Delta B_{12}\right)$ in dependence on the changes of urinary creatine levels ( $\Delta$ creatine/sp. g.) $\left(\Delta=\right.$ Value $_{\text {Last day }}-$ Value $\left._{\text {Fist day }}\right)$ as a result of 30 days of creatine supplementation.

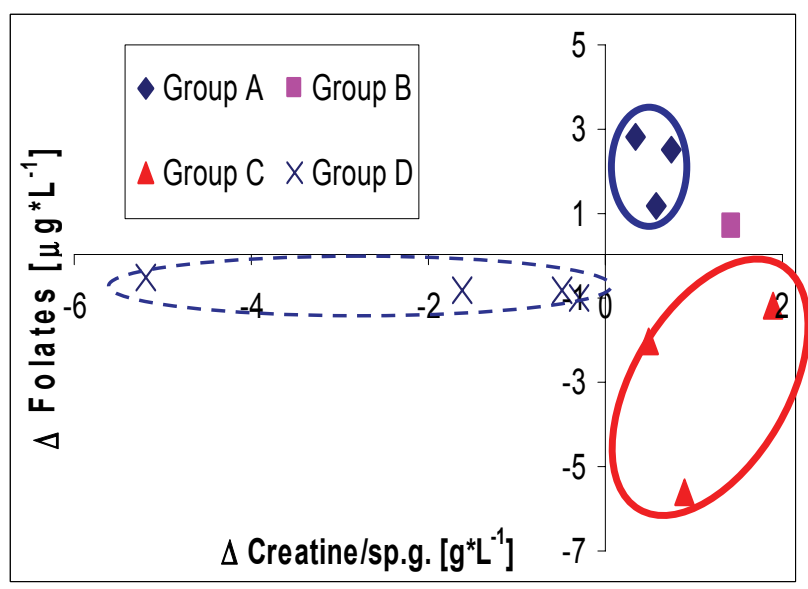

Fig. 2. The changes of blood folates ( $\Delta$ folates) in dependence on the changes of urinary creatine levels ( $\Delta$ creatine/sp. g.) $(\Delta=$ Value $_{\text {Last day }}-$ Value $_{\text {Fist day }}$ ) as a result of 30 days of creatine supplementation.

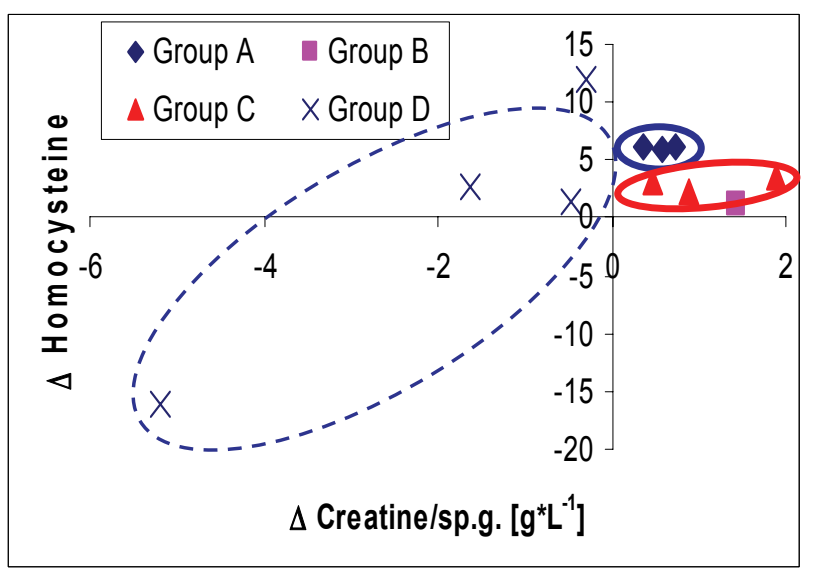

Fig. 3. The changes of blood homocysteine ( $\Delta$ homocysteine) in dependence on the changes of urinary creatine levels ( $\Delta$ creatine/sp. g.) $\left(\Delta=\right.$ Value $_{\text {Last day }}-$ Value $\left._{\text {Fist day }}\right)$ as a result of 30 days of creatine supplementation.

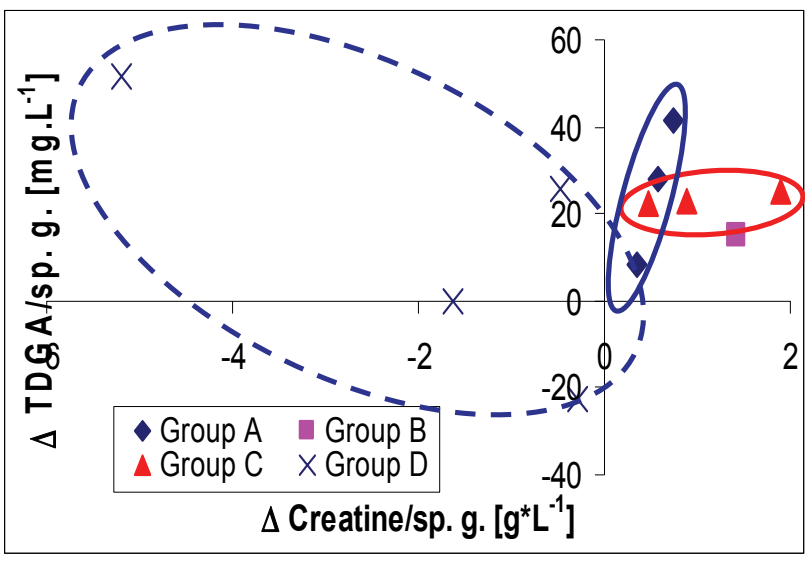

Fig. 4. The changes of urinary thiodiglycolic acid ( $\triangle \mathrm{TDGA} / \mathrm{sp}$. g.) in dependence on the changes of urinary creatine levels ( $\Delta$ creatine/sp. g.) $\left(\Delta=\right.$ Value $_{\text {Last day }}-$ Value $\left._{\text {Fist day }}\right)$ as a result of 30 days of creatine supplementation.

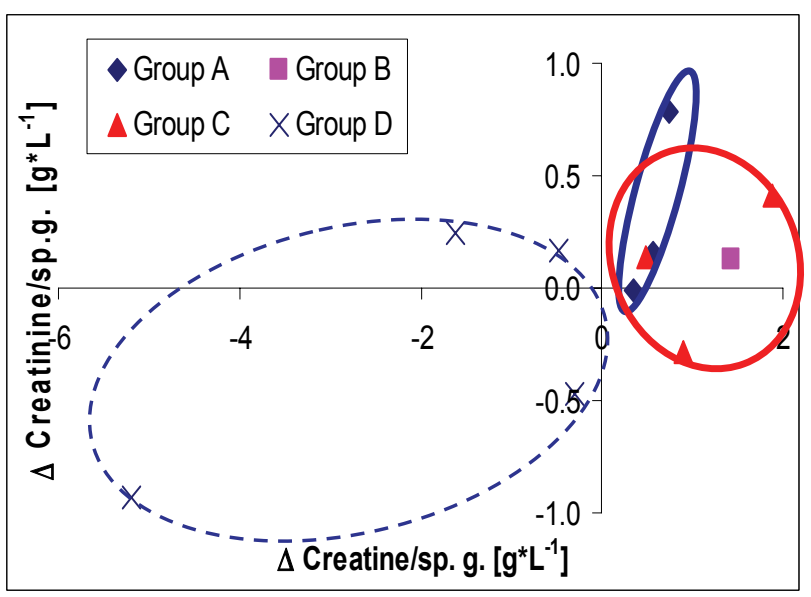

Fig. 5. The changes of urinary creatinine ( $\Delta$ creatinine/sp. g.) in dependence on the changes of urinary creatine levels ( $\Delta$ creatine/sp. g.) $\left(\Delta=\right.$ Value $_{\text {Last day }}-$ Value $\left._{\text {Fist day }}\right)$ as a result of 30 days of creatine supplementation.

The values presented in Figures 1 - 5 enable to show how one month of regular creatine intake affected the enzymatic systems concerning vitamin $\mathrm{B}_{12}$, folates, HoCySH and TDGA, and how it affected the excretion of creatinine into urine.

Group A

In volunteers of group A after one month of regular CR administration only a small amount of unused CR was excreted into urine. The high uptake of CR was accompanied by higher consumption of vitamin $\mathrm{B}_{12}$, therefore its level in blood decreased on average by $14 \%$ (Fig. 1). Levels of folates and of $\mathrm{HoCySH}$ in blood increased by 31-64 \% and 79-127 \%, respectively (indicating decreased consumption of folates and HoCySH) (Figs 2 and 3). 
The amount of TDGA increased proportionally to the amount of unused CR excreted into urine (Fig. 4), similarly as did creatinine (from 8.4 to $41.6 \mathrm{mg} . \mathrm{l}^{-1}$, and 0.01 to 0.78 g. $^{-1}$ ) (Fig. 5).

\section{Group B}

This group, represented by a single man (No. 4) with high initial levels of both vitamins ( $B_{12} 670 \mathrm{ng} . \mathrm{l}^{-1}$ and folates $16.3 \mu \mathrm{g} . \mathrm{l}^{-1}$ ), was characterized by increased levels of vitamin $\mathrm{B}_{12}(+13 \%)$ and folates $(+4.3 \%)$ after $\mathrm{CR}$ administration (Table 1, Figs 1 and 2). HoCySH level increased only moderately (Fig. 3). There was more unused $\mathrm{CR}$ washed out into urine than in group $\mathrm{A}$ $\left(+1.79\right.$ g. $\left.^{-1}\right)$ (Fig. 5). Although the levels of TDGA (Fig. 4) and of creatinine increased, they did not exceed normal values.

\section{Group C}

The men No. 5, 6 and 7 (group C) reacted to CR administration by opposite changes of vitamin $B_{12}$ and folate levels than did the men of group A (Table 1, Figs 1 and 2). The average level of vitamin $B_{12}$ increased by $+13 \%$, whereas that of folates decreased by $-34.1 \%$. The increase of HoCySH level was about one half $(+45 \%)$ of that found in group A (+96\%) (Fig. 3).

The proband No. 5 exhibited the lowest content of unused CR (0.5 g. l $\left.^{-1}\right)$ in urine and the highest level of vitamin $B_{12}$ in blood (Fig. 1).

The proband No. 6, whose vitamin $\mathrm{B}_{12}$ level did not change and the folate level decreased only slightly (Figs 1 and 2), had the highest CR increase in urine from all the 11 men (from 0 to 1.9 g. $1^{-1}$ ). HoCySH levels in blood increased considerably (from 7.9 to $11.5 \mu \mathrm{mol} .1^{-1}$, i.e. by $46 \%$ ), and those of creatinine and TDGA in urine rose from 1.05 to $1.45 \mathrm{~g} .1^{-1}$ and from 0 to $25.3 \mathrm{mg} . \mathrm{l}^{-1}$, respectively (Figs 4 and 5).

A different response to administered $\mathrm{CR}$ was observed in the proband No. 7. His high level of urinary CR before the first administration of CR (4.38 g. $\mathrm{l}^{-1}$ ) increased to $5.27 \mathrm{~g} . \mathrm{l}^{-1}$. This was accompanied by the highest decrease of folates $(-51 \%)$ among all the 11 volunteers (Fig. 2). The already low level of creatinine decreased from 0.87 to 0.59 g. $1^{-1}$ (Fig. 5) and the level of TDGA/sp. g. increased from 0 to $25.3 \mathrm{mg} . \mathrm{l}^{-1}$ (Fig. 4).

\section{Group D}

The CR administration paradoxically decreased or completely prevented excretion of $\mathrm{CR}$ into urine and did not affect markedly the metabolism of folates (Fig. 1).
The men of group D reacted most notably by changes of HoCySH level (from $-48 \%$ to $+238 \%$ ) (Fig. 3 ) on the decreased consumption of vitamin $\mathrm{B}_{12}$ (more of it went to blood) (from $3.8 \%$ to $25 \%$ ).

The men in this group also differed from each other most markedly (Figs 1-5). The CR application had a relatively small effect in man No. 8 . There were little changes in $\mathrm{CR}$ excretion into urine $(\mathrm{CR} / \mathrm{sp}$. g. from 1.53 to $1.05 \mathrm{~g} .1^{-1}$ ), in the levels of folates (from 5.1 to $4.8 \mu \mathrm{g} . \mathrm{l}^{-1}$ ), vitamin $\mathrm{B}_{12}$ (from 846 to $865 \mathrm{ng} . \mathrm{l}^{-1}$ ) or HoCySH (from 5.0 to $7.6 \mu \mathrm{mol}^{-1}$ ) in blood. The low level of creatinine increased from 0.69 to 0.85 g. $1^{-1}$, and even the TDGA/sp. g. rose from 0 to $26.0 \mathrm{mg} . \mathrm{l}^{-1}$.

In man No. 9, with accidentally discovered hyperhomocysteinemia, the $\mathrm{CR}$ administration caused a small decrease of CR (from 0.59 to $0.30 \mathrm{~g} . \mathrm{l}^{-1}$ ), accompanied by the highest increase of vitamin $\mathrm{B}_{12}$ level (by $25 \%$ ), the most pronounced decrease of $\mathrm{HoCySH}$ level (from 33.3 to $17.1 \mu \mathrm{mol} .1^{-1}$ ) (Figs 1 and 3 ) and those of creatinine and TDGA in urine from 1.69 to $1.23 \mathrm{~g} . \mathrm{l}^{-1}$ and from 22.5 to $0.0 \mathrm{mg} . \mathrm{l}^{-1}$, respectively (Figs 4 and 5).

In man No. 10 the strong decrease of CR in urine (CR/sp. g. from 1.62 g..$^{-1}$ to 0 g..$^{-1}$ ) was accompanied by the highest increase of HoCySH level in blood among all 11 tested probands (from 5.0 to $16.9 \mu \mathrm{mol} . \mathrm{l}^{-1}$, i.e. by $238 \%$ (Fig. 3), which is beyond the limit of mild hyperhomocysteinemia.

In men No. 9 and 10 the conditions for TDGA formation did not occur (Fig. 4). This took place in man No. 11 with the greatest decrease of urinary CR (CR/sp. g. from 5.2 to $\left.0 \mathrm{~g} . \mathrm{l}^{-1}\right)$. No. 11 had the highest increase of TDGA level in urine (TDGA/sp. g. from 0 to $51.4 \mathrm{~g} .1^{-1}$ ), the greatest decrease of creatinine level among all the 11 probands (Fig. 5), and only a small increase of $\mathrm{HoCySH}$ and vitamin $\mathrm{B}_{12}$ levels with a small decrease of folates (Figs 1 - 3).

\section{Discussion}

$\mathrm{CR}$ administered regularly as a food supplement during one month, had disturbed the equilibrium among the compounds participating in its endogenous formation. Those are glycine and arginine in kidneys, and the precursors of S-adenosylmethionine (S-AM) in liver (Murray et al. 2003). The detailed scheme of suggested metabolic pathways, describing the transformation of arginine, glycine, and $\mathrm{S}$-adenosylmethionine (S-AM) to $\mathrm{CR}$ is depicted in Figure 6. 


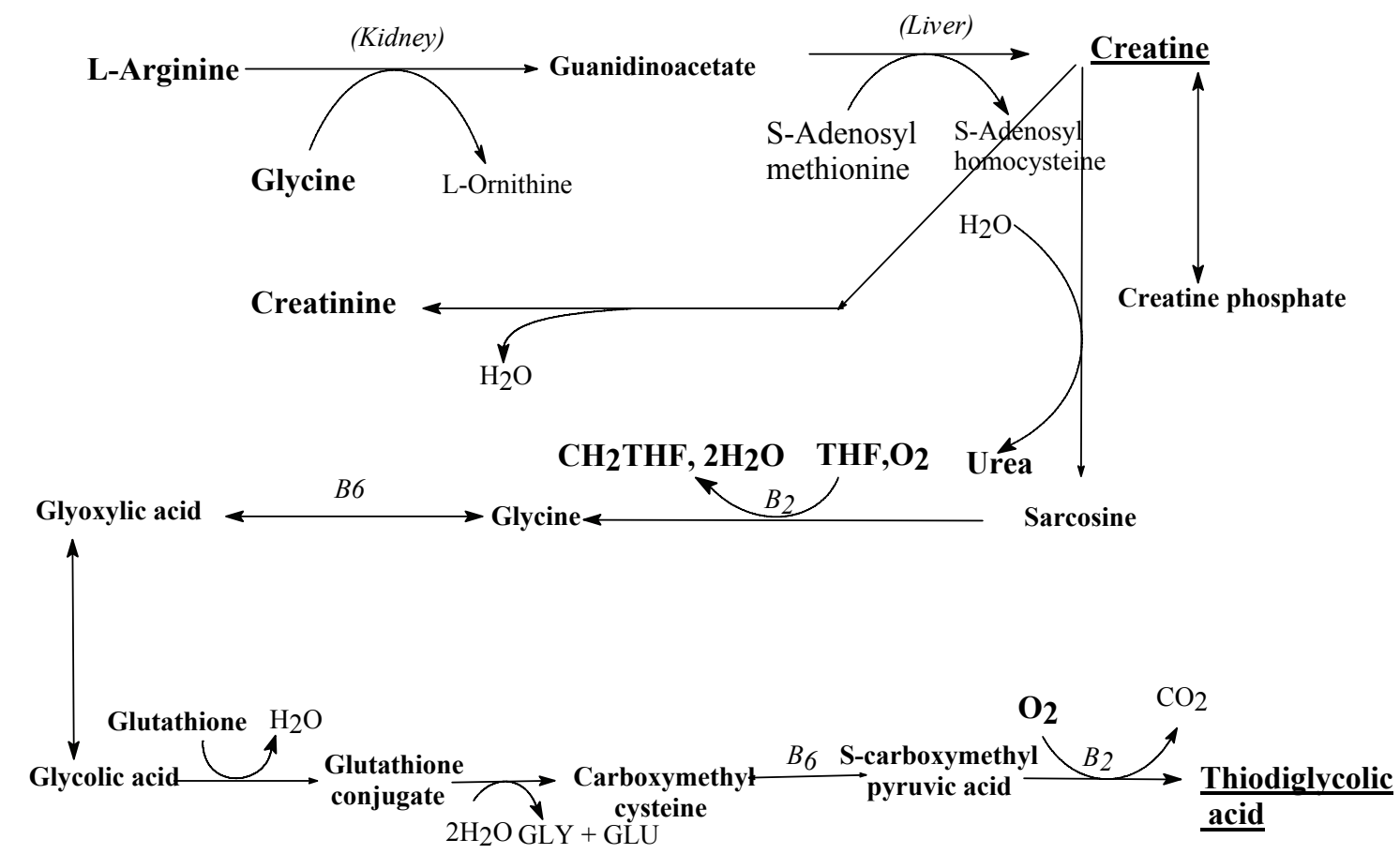

Fig. 6. Suggested metabolic pathways describing the transformation of arginine, glycine, and S-Adenosyl methionine (S-AM) to CR. Oxidative pathway of $C R$ into urea involves vitamins $B_{2}, B_{6}$, tetrahydrofolate (THF) and glutathione, with urea and TDGA (besides others) as final products. The other (non oxidative) metabolic pathways aim one to the non-enzymatic creatinine formation (excreted from the human body) and the other one to creatine phosphate.

The scheme describes the oxidative pathway of $\mathrm{CR}$ involving vitamins $\mathrm{B}_{2}, \mathrm{~B}_{6}$, tetrahydrofolate (THF) and glutathione, with urea and TDGA (besides others) as final products. The other (non-oxidative) metabolic pathways represent the non-enzymatic creatinine formation (excreted from the human body) and the other pathway to creatine phosphate. Up to $70 \%$ of the generated S-AM is used for methylation of guanidinoacetate, which process terminates the formation of CR in liver. ATP is thereby used as energy source, and HoCySH and adenosine are set free. In the following, both compounds participate again in the generation of cell energy. HoCySH as a source of cysteine mediates the transport of protons and electrons from nutrients into the respiratory chain (Murray et al. 2003).

Each man, studied in the groups A, B, C and D, utilized in his own way the compounds, by means of which he would normally generate CR. That is made possible by the high number of enzymatic reactions, which can affect the endogenous synthesis of CR. The interaction between folates, vitamin $\mathrm{B}_{12}$ and HoCySH is fundamental for the regulatory system that monitors utilization of serine, the source of $1 \mathrm{C}$ and $2 \mathrm{C}$ units, necessary for processes catalyzed by them. Glycine and serine are interchangeable by means of folates. An inexhaustible source of serine is D-3-phosphoglycerate. Whether it will produce serine or not, depends on suitable redox conditions in the metabolism of sugars.

We presume that due to administered creatine the molecules of glycine, arginine and S-AM, utilized for endogenous CR synthesis, could enter into other enzymatic reactions, and alter the physiological coordinated recycling of compounds in phospholipid metabolism and in other connected cycles. The pathways differ in lower or higher participation of vitamin $\mathrm{B}_{12}$, HoCySH and folates.

Our results have shown that administered CR does not merely replace the endogenous synthesis of $\mathrm{CR}$ and that its surplus is not excreted by urine as creatinine. When the amount of creatinine excreted at the beginning of the experiment differed markedly from that excreted at the end, then the administered CR evidently caused considerable discrepancies in the metabolic pathways connected with synthesis or degradation of CR.

It follows from the above results that everybody is sensitive in a different way to the changes in nutrition, represented in our case by daily administration of CR. Thus the equilibrium in metabolic processes, which are 
the basis of respiratory activity and of energy formation, is adjusted for everyone in a different way. The individual character of metabolic pathways of each person has to be respected in the search for cure of the anomalies.

Importance of HoCySH for formation and utilization of $C R$

The regular intake of $\mathrm{CR}$ increased $\mathrm{HoCySH}$ levels in all men with exception of one man from Group D with accidentally found hyperhomocysteinemia, in whom its level decreased.

An increase in HoCySH level can be explained by inability of the men to utilize it completely in other processes than in the CR synthesis. There exist three enzymatic reactions for utilization of HoCySH. One of them, catalyzed by methionine synthetase (E.C. 2.1.1.13), occurs under very complicated conditions, and requires participation of folates and vitamin $B_{12}$. It was suppressed by administered $\mathrm{CR}$ in group $\mathrm{A}$, as indicated by high increase of $\mathrm{HoCySH}$ and of $\mathrm{N}^{5}$-methyltetrahydrofolate (the only folate form present in human blood) (Pristoupilova and Pristoupil 1997). The other reaction, catalyzed by betaine-homocysteine S-methyltransferase (E.C. 2.1.1.5), takes place without vitamin $B_{12}$ and without direct participation of folates, the level of both being increased in blood in the group B. Methionine, formed in these two enzymatic reactions, becomes the donor of methyl group after the reaction with ATP. The S-AM, produced in this way, is used, among others, for $\mathrm{CR}$ formation. Both methionine synthetases participate in formation and degradation of phospholipids and/or choline (Murray et al. 2003). A third enzymatic reaction, into which $\mathrm{HoCySH}$ enters together with serine, is catalyzed by cystathionine beta-synthetase (E.C. 4.2.1.22). It changes HoCySH into cystathionine, which is decomposed to cysteine and homoserine. Further processing of homoserine needs the presence of vitamin $\mathrm{B}_{12}$, for transformation of methylmalonyl-CoA derived from homoserine into succinyl-CoA in mitochondria.

This last step, catalyzed by vitamin $B_{12}$, is common with degradation of fatty acids with odd number of carbon atoms. This is also the only way how fatty acids can be utilized for glycogenesis (Murray et al. 2003). The original inability of the man with hyperhomocysteinemia from D group to utilize $\mathrm{HoCySH}$, was probably due to a defect of the system providing serine for reaction with $\mathrm{HoCySH}$ without participation of vitamin $\mathrm{B}_{12}$. The administered $\mathrm{CR}$ supported transformation of more HoCySH into cysteine and homoserine through cystathionine synthase, and into methionine through betaine-homocysteine methyltransferase.

The only mild increase of HoCySH level in groups $\mathrm{B}$ and $\mathrm{C}$ was probably due to lack of folates in proper coenzymatic forms. In group $\mathrm{D}$ it varied depending on vitamin $\mathrm{B}_{12}$ consumption. The absolute value of the initial levels of folates, vitamin $B_{12}$ and HoCySH did not affect utilization of CR in any of the above mentioned groups.

Relationship between the way of CR processing, thiocompound metabolism and changes in oxidation reactions

Oxidation of sulfur atom, which is contained in TDGA molecule and whose source can also be $\mathrm{HoCySH}$ (Navratil et al. 2004, Navratil et al. 2007), can proceed up to inorganic sulfate. However, the increase of TDGA level in urine was not always parallel with the increase of HoCySH level in blood.

It can be seen in Figures 1, 2 and 4 that in each group of men HoCySH, folates and vitamin $\mathrm{B}_{12}$ participated to a different extent on the increase of TDGA level in urine, caused by the administered CR. That was caused by the replacement of glycine, arginine and ATP, consumed in endogenous formation of CR. At the same time, it decreased reutilization of $\mathrm{HoCySH}$, methyltetrahydrofolate, tetrahydrofolate and vitamin $\mathrm{B}_{12}$, which are also indispensable for CR synthesis.

In men of group $\mathrm{A}$, the more unused $\mathrm{CR}$ was excreted into urine, the more unused $\mathrm{HoCySH}$ and folates (Fig. 2) went to blood, and the more TDGA appeared in urine (Fig. 4). In group A in TDGA formation participated to a higher extent vitamin $B_{12}$, as its level in blood decreased (Fig. 1).

In groups $\mathrm{B}$ and $\mathrm{C}$ the administration of $\mathrm{CR}$ induced only a small increase of TDGA level (Fig. 4) and a small increase of HoCySH level (Fig. 3). The changes of levels of folates and vitamin $B_{12}$ were higher than in group A (Figs. 1 and 2).

In the group $\mathrm{D}$, the more $\mathrm{CR}$ was processed under the participation of vitamin $\mathrm{B}_{12}$ and $\mathrm{HoCySH}$, i.e. the less of them was in blood and of $\mathrm{CR}$ in urine, the more TDGA was in urine. On the contrary, the less of $\mathrm{HoCySH}$ and of vitamin $\mathrm{B}_{12}$ participated in processing of $\mathrm{CR}$, the higher were their levels in blood and the smaller were CR levels in urine, the less TDGA appeared in urine (Figs 1 and 2). 


\section{Conclusions}

In human body, CR is endogenously synthesized and, in addition, it is taken in food as part of meat victuals. In that case, its endogenous production adjusts itself to the exogenous intake with the help of vitamin $B_{12}$ and folates. This can be deduced from reciprocal changes of their levels in blood and changes in the utilization of HoCySH in various metabolic pathways. The results, based upon TDGA determination in urine, agree with our assumption that the main source of $2 \mathrm{C}$ units, from which TDGA is formed in healthy individuals, is the degradation of glycine and serine, respectively.

According to changes in the levels of vitamin $\mathrm{B}_{12}$ and folates in blood and those of $\mathrm{CR}$ in urine, the tested men were divided into four groups (A, B, C and D). This separation was connected with increase of the HoCySH level in blood and, independently, also with increase of TDGA level in urine.

Our study has demonstrated that healthy individuals - sportsmen - include CR in their metabolic pathways individually according to their state of metabolism. In some cases such differences can markedly affect their health and physical fitness.

Group $\mathrm{D}$ reacted in the most sensitive way by changing levels of vitamin $\mathrm{B}_{12}$ and HoCySH in response to $\mathrm{CR}$ administration. In that group, containing accidentally a man with hyperhomocysteinemia, the thorough utilization of the administered CR resulted in a decrease of HoCySH level in blood by one half and in disappearance of TDGA from urine.

In agreement with our results published earlier (Navratil et al. 2007, Pristoupilova et al. 2005), the values of creatinine in spot urine changed according to metabolic conditions. Hence the generally recommended recalculation of the levels of compounds excreted into urine per creatinine concentration does not seem to be suitable for all cases, and it can be replaced by correction per specific gravity of urine.

Very simple procedures of urine analysis for TDGA, CR and creatinine can yield very interesting and important information on the changes in human metabolism without necessity of blood withdrawal.

\section{Conflict of Interest}

There is no conflict of interest.

\section{Acknowledgements}

This research has been supported by the GA AV ČR (project No. IAA400400806), by the Czech Ministry of Education, Youth and Sports (Research Projects No. 0021620807, MSM 0021620864).

\section{References}

BARDODEJ Z, DAVID A, SEDIVEC V, SKRAMOVSKY S, TEISINGER J: Exposure Tests in Industrial Toxicology. (in Czech), Avicenum, Prague, 1989.

BAREK J, DODOVA E, NAVRATIL T, YOSYPCHUK B, NOVOTNY L, ZIMA J: Voltammetric determination of N,N-dimethyl-4-amine-carboxyazobenzene at a silver solid amalgam electrode. Electroanalysis 15: 1778$1781,2003$.

BAREK J, FISCHER J, NAVRATIL T, PECKOVA K, YOSYPCHUK B: Silver solid amalgam electrodes as sensors for chemical carcinogens. Sensors 6: 445-452, 2006.

BAREK J, FISCHER J, NAVRATIL T, PECKOVA K, YOSYPCHUK B, ZIMA J: Nontraditional electrode materials in environmental analysis of biologically active organic compounds. Electroanalysis 19: 2003-2014, 2007.

BECKMAN_COULTER: Access ${ }^{\circledR}$ Vitamin B12. http://www.beckman.com/, 2004.

BECKMAN_COULTER: Instruction for Diagnostic Sets and Devices. http://www.immunotech.cz/support.htm, 9.3.2008.

CHYLKOVA J, FADRNA R: Procedure for isotachophoretic determination of thiodiglycolic acid in urine using desalination of the analyzed sample. Chem Listy 98: 260-263, 2004.

DLASKOVA Z, NAVRATIL T, HEYROVSKY M, PELCLOVA D, NOVOTNY L: Voltammetric determination of thiodiglycolic acid in urine. Anal Bioanal Chem 375: 164-168, 2003.

DOU C, XIA DY, ZHANG LQ, CHEN XR, FLORES P, DATTA A, YUAN C: Development of a novel enzymatic cycling assay for total homocysteine. Clin Chem 51: 1987-1989, 2005. 
ERMAKOVA IT, STAROVOITOV II, TIKHONOVA EB, SLEPEN'KIN AV, KASHPAROV KI, BORONIN AM: Bioutilization of thiodiglycol, the product of mustard detoxification: isolation of degrading strains, study of biodegradation process and metabolic pathways. Process Biochem 38: 31-39, 2002.

FELBER S, SKLADAL D, WYSS M, KREMSER C, KOLLER A, SPERL W: Oral creatine supplementation in Duchenne muscular dystrophy: a clinical and ${ }^{31} \mathrm{P}$ magnetic resonance spectroscopy study. Neurol Res 22: 145$150,2000$.

HESPEL P, OP'T EIJNDE B, DERAVE W, RICHTER EA: Creatine supplementation: exploring the role of the creatine kinase/phosphocreatine system in human muscle. Can J Appl Physiol 26: S79-S102, 2001.

KLINLAB: Laboratory KlinLab. http://www.klinlab.cz/en/, 9. 2. 2010a.

LEE TS, CHAN SH, WEIGAND WA, BENTLEY WE: Biocatalytic transformation of [(2-hydroxyethyl)thio]acetic acid and thiodiglycolic acid from thiodiglycol by Alcaligenes xylosoxydans ssp xylosoxydans (SH91). Biotechnol Prog 16: 363-367, 2000.

MURRAY RK, GRANNER KD, MAYES PA, RODWELL VW: Harper's Biochemistry. McGraw-Hill Companies USA, 2003.

NAVRATIL T, KOPANICA M: Analytical application of silver composite electrode. Crit Rev Anal Chem 32: 153-166, 2002a.

NAVRATIL T, KOPANICA M: Lead determination on silver composite electrodes using the effect of underpotential deposition. Chem Listy 96: 111-116, 2002 b.

NAVRATIL T, KOPANICA M, KRISTA J: Anodic stripping voltammetry for arsenic determination on composite gold electrode. Chem Anal (Warsaw) 48: 265-272, 2003.

NAVRATIL T, PETR M, SENHOLDOVA Z, PRISTOUPILOVA K, PRISTOUPIL TI, HEYROVSKY M, PELCLOVA D, KOHLÍKOVA E: Diagnostic significance of urinary thiodiglycolic acid as a possible tool for studying the role of vitamins $\mathrm{B}_{12}$ and folates in the metabolism of thiolic substances. Physiol Res 56: 113-122, 2007.

NAVRATIL T, SENHOLDOVA-DLASKOVA Z, HEYROVSKY M, PRISTOUPILOVA K, PRISTOUPIL TI, PELCLOVA D: Excretion of thiodiglycolic acid in urine affected by some victuals and cetirizine. Anal Lett 37: 1093-1102, 2004.

NAVRATIL T, KOHLIKOVA E, PETR M, HEYROVSKY M, PELCLOVA D, PRISTOUPILOVA K, PRISTOUPIL TI, SENHOLDOVA Z: Contribution to explanation of the effect of supplemented creatine in human metabolism. Food Chem 112: 500-506, 2009.

PERSKY AM, BRAZEAU GA: Clinical Pharmacology of the Dietary Supplement Creatine Monohydrate. Department of Pharmaceutics, College of Pharmacy, University of Florida, Gainesville, 2001.

PETR M: Metabolic Pathways Leading to Excretion of Thiodiglycolic Acid into Urine Affected by Creatine Supplementation. PhD Thesis, Charles University in Prague, Prague, 2007.

PRISTOUPILOVA K, PRISTOUPIL TI: Role of Folates in Metabolic Pathways. Academia, Prague, 1997.

PRISTOUPILOVA K, PRISTOUPIL TI, NAVRATIL T, HEYROVSKY M, SENHOLDOVA Z, PELCLOVA D: Daily rhythm of urinary excretion of thiodiglycolic acid (TDGA) in humans under different health conditions and treatment. Anal Lett 38: 613-627, 2005.

SAMCOVA E, KVASNICOVA V, URBAN J, JELINEK I, COUFAL P: Determination of thiodiglycolic acid in urine by capillary electrophoresis. J Chromatogr A 847: 135-139, 1999.

SEBKOVA S, NAVRATIL T, KOPANICA M: Silver composite electrode for voltammetric determination of halogenides. Anal Lett 37: 603-628, 2004.

SEBKOVA S, NAVRATIL T, KOPANICA M: Graphite composite electrode in voltammetry. Anal Lett 38: 1747-1758, 2005.

SENHOLDOVA-DLASKOVA Z: Polarographic/Voltammetric Determination of Thiodiglycolic Acid as the Indicator of Exposure to Vinylchloride. Ph.D. Thesis, University of Pardubice, Pardubice, 2002.

STEVENTON GB: Diurnal variation in the metabolism of S-carboxymethyl-L-cysteine in humans. Drug Metab Dispos 27: 1092-1097, 1999.

TARNOPOLSKY M, MARTIN J: Creatine monohydrate increases strength in patients with neuromuscular disease. Neurology 52: 854-857, 1999. 
WEBBER M: Creatine Supplementation. http://www.faccioni.com/Reviews/creatine.htm, 2.4.2006.

WICKRAMASINGHE SN, FIDA S: Correlations between Holo-Transcobalamin-Ii, Holo-Haptocorrin, and total $\mathrm{B}_{12}$ in serum samples from healthy subjects and patients. J Clin Pathol 46: 537-539, 1993.

YOSYPCHUK B, NAVRATIL T, LUKINA AN, PECKOVA K, BAREK J: Solid amalgam composite electrode as a new sensor for the determination of biologically active compounds. Chem Anal (Warsaw) 52: 897-910, 2007.

YOSYPCHUK B, NOVOTNY L: Electrodes of nontoxic solid amalgams for electrochemical measurements. Electroanalysis 14: 1733-1738, 2002a.

YOSYPCHUK B, NOVOTNY L: Nontoxic electrodes of solid amalgams. Crit Rev Anal Chem 32: 141-151, 2002b. 